\title{
Emotion and cognition in high and low stress sensitive mouse strains: a combined neuroendocrine and behavioral study in BALB/c and C57BL/6J mice
}

\author{
Vera Brinks*, Maaike van der Mark, Ronald de Kloet and Melly Oitzl \\ Division of Medical Pharmacology, LACDR/LUMC, Leiden University, The Netherlands \\ Edited by: Carmen Sandi, Ecole Polytechnique Federale de Lausanne, Switzerland \\ Reviewed by: Bianca Topic, University of Düsseldorf, Germany \\ Carmen Sandi, Ecole Polytechnique Federale de Lausanne, Switzerland
}

Emotionally arousing experiences and stress influence cognitive processes and vice versa. Understanding the relations and interactions between these three systems forms the core of this study. We tested two inbred mouse strains (BALB/c, C57BL/6J; male; 3-month-old) for glucocorticoid stress system markers (expression of MR and GR mRNA and protein in hippocampus, amygdala, and prefrontal cortex; blood plasma corticosterone), used behavioral tasks for emotions and cognitive performance (elevated plus maze, holeboard) to assess the interdependence of these factors. We hypothesize that BALB/c mice have a stress-vulnerable neuroendocrine phenotype and that emotional expressions in BALB/c and C57BL/6J mice will differentially contribute to learning and memory. We applied factor analyses on emotional and cognitive parameters to determine the behavioral structure of BALB/c and C57BL/6J mice. Glucocorticoid stress system markers indeed show that BALB/c mice are more stress-vulnerable than C57BL/6J mice. Moreover, emotional and explorative factors differed between naïve BALB/c and C57BL/6J mice. BALB/c mice display high movement in anxiogenic zones and high risk assessment, while C57BL/6J mice show little movement in anxiogenic zones and display high vertical exploration. Furthermore, BALB/c mice are superior learners, showing learning related behavior which is highly structured and emotionally biased when exposed to a novel or changing situation. In contrast, C57BL/6J mice display a rather "chaotic" behavioral structure during learning in absence of an emotional factor. These results show that stress vulnerability coincides with more emotionality, which drives well orchestrated goal directed behavior to the benefit of cognition. Both phenotypes have their advantage depending on environmental demands.

Keywords: glucocorticoid stress system, MR, GR, emotion, cognition, BALB/c, C57BL/6J

\section{INTRODUCTION}

Emotion and cognition are two well studied aspects of human and rodent behavior. While increasing data suggests an interaction between the two (Phelps, 2006), a third interacting factor, the glucocorticoid stress system, also becomes more apparent. Emotions profoundly influence ongoing and long-term cognitive processes (Acevedo et al., 2006; Blair et al., 2007; Contarino et al., 1999; Dolcos and McCarthy, 2006; Gerlai et al., 2002; Ohl et al., 2003; Steidl et al., 2006; Wall and Messier, 2000). In addition, cognition can also disrupt the response to emotional stimuli (Blair et al., 2007). Interestingly, emotion and cognition might also interact in the development of stress-related diseases; Hayden and colleagues have shown that cognitive vulnerability to depression can originate from early emerging differences in the expression of positive emotions (Hayden et al., 2006). Only few studies have aimed at testing the interaction

\footnotetext{
* Correspondence: Division of Medical Pharmacology, LACDR/LUMC, Leiden University, P. 0. Box 9502, 2300 RA Leiden, The Netherlands. Tel.: +3171 5274428, Fax: +3171 5274715. e-mail: v.brinks@lacdr.leidenuniv.nl

Received: 05 Nov. 2007; paper pending published: 20 Nov. 2007; accepted: 05 Dec. 2007; Published online: 30 Dec. 2007

Full citation: Frontiers in Behavioral Neuroscience (2007) 1:8 doi: 10.3389/neuro.08/ 008.2007

Copyright (C) 2007 Brinks, van der Mark, de Kloet and Oitzl. This is an open-access article subject to an exclusive license agreement between the authors and the Frontiers Research Foundation, which permits unrestricted use, distribution, and reproduction in any medium, provided the original authors and source are credited.
}

between emotion, cognition, and the glucocorticoid stress system in mice. Recently, we have reported that increasing chronic plasma corticosterone concentrations, and therefore differential mineralo and glucocorticoid receptor (MR, GR) activation, augments emotional arousal, and impairs cognitive performance of C57BL/6J mice (Brinks et al., 2007b). Based on our seminal observations of glucocorticoid actions (Oitzl and de Kloet, 1992b; Oitzl et al., 1994; Oitzl et al., 2001b) we have developed the concept that both receptor types contribute in complementary fashion to the regulation of ongoing and stress-related behavioral responses: MR in limbic brain facilitates perception and attention and can bias information processing to allow acquisition of a behaviorally adaptive response pattern (Oitzl and de Kloet, 1992a; Zorawski and Killcross, 2002). In contrast, GR promotes memory consolidation and facilitates extinction of responses that are of no more relevance (Bohus and de Kloet, 1981; Oitzl and de Kloet, 1992b; Zorawski and Killcross, 2002). We decided to assess the neuroendocrine and behavioral phenotype of two inbred mouse strains, BALB/C and C57BL6J, that are expected to have a differential regulation of the stress system (Ducottet and Belzung, 2004; Harizi et al., 2007; Roy et al., 2007) in face of emotional expression (Ohl et al., 2001) and cognitive performance (Balogh and Wehner, 2003; Roullet and Lassalle, 1995). This research thus focuses on the interaction between the stress system, emotion, and cognition.

We expect that BALB/C and C57BL/6J mice have distinct central and peripheral markers for stress system activity under resting and activated conditions. Therefore, we will first measure MR and GR mRNA expression and protein in limbic brain areas: hippocampus, prefrontal cortex, and 
amygdala and set the time course of corticosterone secretion in response to novelty. In a second series of experiments, we will determine the behavioral phenotype of the mice. Since initial behavioral reactivity towards a novel environment will influence later cognitive processing (Touyarot et al., 2004), we will observe naïve BALB/c and C57BL/6J mice in the elevated plus maze and modified holeboard to collect a large amount of behavioral variables related to general activity, exploration, and anxiety. To assess if previous stress differentially affects ongoing behavior, separate groups of mice will be exposed to the elevated plus maze after 60 minutes sensory exposure to a rat (Grootendorst et al., 2001; Linthorst et al., 2000). Next, we will use the modified holeboard for simultaneous emotional and cognitive testing during different stages of task acquisition, retrieval, and reversal learning. Moreover, factor analyses on emotional and cognitive parameters will be performed to obtain a more comprehensive insight in the strain dependent behavioral structure during the learning process. We expect that BALB/c mice will display glucocorticoid stress system markers indicative for a stress vulnerable phenotype; high stress induced corticosterone concentrations and an altered MR/GR balance compared to C57BL/6J mice. In addition, we expect that emotional expressions will differentially contribute to learning and memory in BALB/C and C57BL/6J mice.

\section{MATERIALS AND METHODS \\ Animals}

$\mathrm{BALB} / \mathrm{C}$ and C57BL/6J male mice (a total of $n=79$ per strain; 12-weekold) were obtained from Elevage Janvier (Le Genest Saint Isle, France). After arrival, the mice were housed individually in the experimental room with sawdust bedding, water, and food ad libitum, at $20^{\circ} \mathrm{C}$ with controlled humidity under a 12:12 hours light/dark cycle (lights on at 08.00 hours.) for 1 week. Male Long-Evans rats (male $n=8$ ) from our own breeding stock were used to activate the stress system of mice. Experiments were performed between 09.00 and 13.30 hours and were approved by the committee on Animal Health and Care from the Leiden University, The Netherlands, in compliance with the EC Council Directive of November 1986 (86/609/EEC) for the care and use of laboratory animals.

\section{Experiment 1: the neuroendocrine phenotype: markers of stress system activity}

In situ hybridization of MR and GR mRNA expression. Eight mice per strain were decapitated between 09.00 and 10.00 hours, brains were isolated, frozen in isopentane on dry-ice and kept at $-80^{\circ} \mathrm{C}$ until sectioning. For MR and GR mRNA measurements, frozen brains were sectioned at $12 \mu \mathrm{m}$ using a $-20^{\circ} \mathrm{C}$ cryostat microtome coronal sections on the level of the prefrontal cortex, hippocampus, and amygdala (Figure 1). Sections were thaw mounted on poly-L-lysine-coated slides $(0.001 \%)$, and kept at $-80^{\circ} \mathrm{C}$ until further use. In situ hybridizations using ${ }^{35} \mathrm{~S}$-labeled ribonucleotide probes (MR, GR,) were performed as described before (Schmidt et al., 2003).
Sections were fixed in $4 \%$ paraformaldehyde and acetylated in $0.25 \%$ acetic anhydride in $0.1 \mathrm{M}$ triethanolamine/HCl followed by dehydration in increasing concentrations of ethanol. The antisense RNA probes were transcribed from linearized plasmids containing exon 2 of mouse MR and GR. On the slides, $100 \mu$ l hybridization buffer was put containing $20 \mathrm{mM}$ Tris- $\mathrm{HCl}$ (pH 7.4), $50 \%$ formamide, $300 \mathrm{mM} \mathrm{NaCl}, 1 \mathrm{mM}$ EDTA, $1 \times$ Denhardt's, $250 \mu \mathrm{g} / \mathrm{ml}$ yeast transfer RNA, $250 \mu \mathrm{l} / \mathrm{ml}$ total RNA, $10 \mathrm{mg} / \mathrm{ml}$ herring sperm DNA, $5 \%$ dextran sulfate, $0.1 \%$ SDS, $0.1 \%$ sodium thiosulfate together with $1.5 \times 10^{6} \mathrm{cpm}{ }^{35} \mathrm{~S}$-labeled riboprobe (MR or GR). A coverslip was placed over the brain sections followed by $55^{\circ} \mathrm{C}$ overnight incubation. The next day, sections were washed with $2 \times \mathrm{SSC}$, treated with RNaseA $(20 \mathrm{mg} / \mathrm{ml})$, and washed at room temperature in increasingly concentrations of SSC solutions. Finally, sections were washed in $0.1 \times \mathrm{SSC}$ at $65^{\circ} \mathrm{C}$ for 30 minutes and dehydrated with increasing ethanol concentrations. Kodak Biomax MR films were placed on the slides (Eastman Kodak Co., Rochester, NY, USA) for 3 days to measure MR mRNA levels in the hippocampus and prefrontal cortex (PFC) and 6 days for MR mRNA levels in the amygdala. For hippocampal, prefrontal cortex, and amygdala GR mRNA measurements, the films were placed on the slides for 6 days.

The autoradiographs (films) were scanned and optical density (OD) of the areas of interest was determined using image analysis computer software (analySIS 3.1, Soft Imaging System GmbH). All optical density measurements for relative mRNA expression were taken bilaterally on two brain slices per mouse, and corrected for aspecific binding by subtracting background and sense signal. For relative hippocampal MR and GR mRNA measurements, greyvalues of the Cornu Ammonis areas (CA1, CA2, CA3) and dentate gyrus of the hippocampus were measured. For prefrontal cortex measurements, the infra- and prelimbic area was chosen because of connections to other limbic areas, and for amygdala measurements, optical densities for the basolateral amygdala were measured.

Western blotting of GR protein. Sixteen mice per strain were decapitated between 09.00 and 10.00 hours. Eight mouse brains per strain were used for dissection of the complete hippocampus. The prefrontal cortex and amygdala were dissected from the other eight brains. Brain tissue was lysated using $500 \mu \mathrm{l} 1 \times$ RIPA lysisbuffer, homogenized (potter apparatus), and centrifuged $\left(20^{\prime}, 4^{\circ} \mathrm{C}\right.$ at $\left.15000 \mathrm{rpm}\right)$. Protein concentration was measured in the supernatant using a Pierce PCA assay. Next, $15 \mu \mathrm{l}$ samples (containing a total of $30 \mu \mathrm{g}$ protein, filled up with sample buffer, and denaturized at $95^{\circ} \mathrm{C}$ for 5 minutes) were subjected to SDS-PAGE. Blots were blocked in $10 \mathrm{mM}$ Tris- $\mathrm{HCl}(\mathrm{pH} \mathrm{8.0)}$ ), $150 \mathrm{mM} \mathrm{NaCl}$, and $0.05 \%$ Tween 20 containing $5 \%$ non-fat dried milk powder and incubated with the H-300 primary antibody (1:1000, SantaCruz Biotechnology, Santa Cruz, CA) followed by incubation of the Goat anti rabbit IgG (1:5000, Sigma, St. Louis, M0) or the monoclonal anti- $\alpha-$ tubulin antibody (Sigma, 1:2500). As negative and positive control, respectively, sample buffer and GR transfected cos- 1 cells were taken along. After washing, blots were incubated with peroxidase-conjugated
A

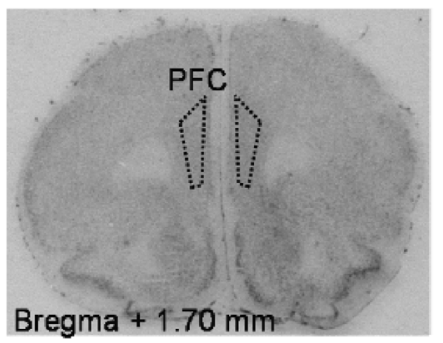

B

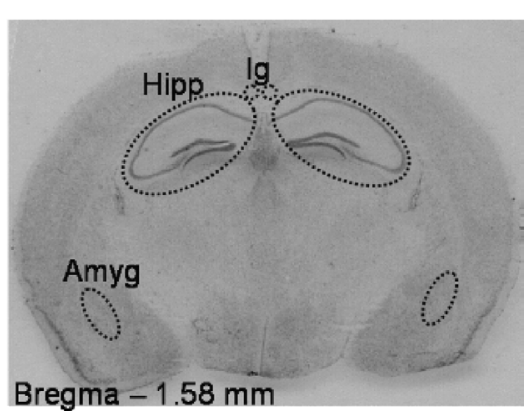

Figure 1. Coronal sections of the mouse brain, stained with cresylviolet. Dotted lines indicate the areas of interest for image analysis of optical density for MR and GR mRNA expression. (A) the infra- and prelimbic areas of the prefrontal cortex (PFC), (B) the hippocampus (Hipp), amygdala (Amyg) and indusium griseum (lg). 
antibodies (1:10 000; Jackson ImmunoResearch Laboratories, West Grove, PA). Blots were washed again and immunoreactive bands were visualized by enhanced chemiluminescence. Finally, the blots were exposed to films for 30 seconds. The autoradiographs (films) were scanned and optical density (OD) of the GR and $\alpha$-tubulin bands from the hippocampus, prefrontal cortex, and amygdala areas were determined using windows Image $\mathrm{J}$ software. GR protein measurements were corrected for total protein ( $\alpha$-tubulin).

Corticosterone response to novelty stress. BALB/C and C57BL/6J mice $(n=35$ per strain) were individually placed in a novel cage containing sawdust bedding. At 5, 30, 60, 120, and 240 minutes mice ( $n=7$ per strain) were decapitated and trunk blood was collected. To estimate basal resting corticosterone, blood was obtained by tail incision 1 day before the experiment ( $n=7$ per strain, randomly chosen). Corticosterone concentrations were determined from $10 \mu \mathrm{l}$ isolated plasma using a commercially available radio immune assay kit with a detection limit of $3 \mathrm{ng} / \mathrm{ml}$ (MP Biomedicals Inc., California, USA).

Experiment 2: the behavioral phenotype: unconditioned behavior in the modified holeboard and elevated plus maze

Apparatus. The modified holeboard consisted of a gray PVC box (50 $\times$ $\left.50 \times 50 \mathrm{~cm}^{3}\right)$ with a gray PVC centerboard $\left(37 \times 20 \mathrm{~cm}^{2}\right)$ on which 10 dark gray cylinders ( $4 \mathrm{~cm}$ height) were staggered in two lines of 5 (Brinks et al., 2007b; Ohl et al., 2003). The bottom of the cylinder is covered by a grid. During testing, the modified holeboard was situated on the floor and a camera placed above the setting allowed later pathway reconstruction from video. Light intensity of the experimental room was set at 80 Lux and a $20 \mathrm{~dB}$ background noise originating from a radio was present.

The elevated plus maze included a center area $\left(6 \times 6 \mathrm{~cm}^{2}\right)$, two open $\left(28 \times 6 \mathrm{~cm}^{2}\right)$, and two closed arms $\left(28 \times 6 \mathrm{~cm}^{2}\right)$ with transparent PVC $(15 \mathrm{~cm}$ high) walls. The floor consisted of gray PVC and the entire setup was elevated on $100 \mathrm{~cm}$ high metal bars. Also here, a camera was placed above the set-up for later pathway reconstruction from video, light intensity was set at $80 \mathrm{Lux}$ and a $20 \mathrm{~dB}$ background noise was present.

Set-ups were cleaned with tap water and dried before each mouse.

Rat stress. Since rats and mice avoid each other in nature, rat exposure is a powerful stressor for a mouse and will produce a profound activation of the glucocorticoid stress system (Linthorst et al., 2000).

Rat stress was performed as described before (Grootendorst et al., 2001). Mice were transported to a room which housed the rats and placed individually in a novel cage with sawdust. One rat was placed in a cage with a grid floor and transparent PVC walls on top of two mouse cages. Physical contact was not possible, while mice could see, hear, and smell the rat. In this room, no background noise was present, light intensity was set at 80 Lux. The mice were subjected to 1 hour of rat stress immediately followed by behavioral testing in the elevated plus maze in an adjacent room.

General experimental procedure. Behavior of naïve BALB/C and C57BL/6J mice ( $n=12$ per strain) was studied during a 5-minute exposure to the modified holeboard and elevated plus maze. The interval between the two tasks was 7 days and tasks were counterbalanced. Rat stress-induced behavior on the elevated plus maze was measured in a separate group of mice ( $n=8$ per strain). Behavioral testing took place in the mouse housing room to prevent transport-induced activation of the stress system.

All mice were placed (i) in the modified holeboard in the same corner facing the wall and (ii) in the elevated plus maze in the center area facing the closed arm.

In depth behavioral observation during modified holeboard testing was performed using a semiautomatic scoring system (Observer, Noldus, Wageningen, The Netherlands). For the modified holeboard, we scored the total number of defecations, sitting, rearing, stretched attends, grooming, centerboard entries, and cylinder visits, as well as the time on the centerboard, sitting, grooming, and the latency to the first centerboard entry.

The behaviors on the elevated plus maze included the total number of defecations, sitting, walking, stretched attends, grooming, rearings, and rim dips. Also the time and entries in the open/closed arms, grooming, sitting, and walking were measured.

During both modified holeboard and elevated plus maze exposure, the total distance moved was measured and pathways were reconstructed (Ethovision, Noldus, Wageningen, The Netherlands).

Experiment 3: the cognitive phenotype: simultaneous emotional expression and cognitive performance estimated in the modified holeboard task

Apparatus. The apparatus is described in Experiment 1. In addition, visual markers were placed on the walls of the room to support distal visual-spatial orientation and rings were placed on the cylinders for proximal visual discrimination. On day 1 , all 10 cylinders on the centerboard were baited with a small piece of almond under and on top of the grid. Placing the almonds under the grid should provide the same odor cue for all cylinders.

On all other days, only three cylinders were baited with a small piece of almond on top of the grid, and marked with a white ring as visual cue. The seven other cylinders contained a non-obtainable almond underneath the grid and were marked with a black ring. This set-up allows visual discrimination as well as spatial location of the baited and non-baited cylinders.

Emotional and cognitive measurements. The behavior of $\mathrm{BALB} / \mathrm{C}$ and C57BL/6J mice ( $n=8$ per strain) was observed, video-taped and analyzed with a semiautomatic scoring system (The Observer Mobile 4.1, Noldus Information Technology, Wageningen, The Netherlands). The behaviors observed were similar as described for the modified holeboard observations in Experiment 2, with the addition of the total number of baited, non-baited and repeated cylinders visited, food rewarded visits, and total number of baits eaten. The latency to the first cylinder visit, the latency to eat the first bait, and the time to finish the task were also measured.

As indication for (i) reference memory, the number of baited cylinder visits was divided by total cylinder visits, and for (ii) working memory, the number of food rewarded cylinder visits was divided by the number of baited cylinders visited. Cognitive parameters such as time to finish the task and reference and working memory were calculated from day 2 onwards.

General experimental procedure. To familiarize the mice with the bait containing cylinders of the modified holeboard task, a cylinder containing a few pieces of almonds was placed in their homecage daily (Brinks et al., 2007b). Also here, behavioral testing took place in the mouse housing room to prevent transport-induced activation of the stress system.

Mice were tested in the modified holeboard over 10 days. On day 1 (all cylinders baited), the mice were allowed to explore the setting for 10 minutes. On all other days, mice were tested for $3 \times 5$ minutes or until eating all baits, with an intertrial interval of 20-30 minutes.

On days $2-5$, three cylinders were baited and visually marked. On days 6 and 7 , mice were not tested. On day 8 , the same settings as on days 2-5 were used. On day 9, a reversal was introduced: the three baited cylinders, including the white ring, shifted one position. This allowed (i) to determine the effect of a "novel" situation on emotional and cognitive processes and (ii) to estimate if the mice used a spatial or visual discrimination strategy to solve the task. On day 10 , the same settings as on day 9 were used.

\section{Statistical analysis}

For Experiment 1, MR and GR mRNA expression and corticosterone concentrations are represented as mean $\pm \mathrm{SEM}$. Student's $t$-test was 
used to determine strain effects on MR and GR mRNA. Between strain, time, and strain $\times$ time interaction for corticosterone concentrations were determined by general linear model (GLM)-general factorial measurement. Student's $t$-test was used to determine differences in basal and novelty induced corticosterone concentrations.

For Experiment 2, the behavioral data are represented as mean \pm SEM. Because the order of testing did not influence outcome, modified holeboard and elevated plus maze data of the two testing days was pooled. Between strain differences were determined with a GLMmultivariate measurement. Stress-induced and strain $\times$ stress interaction for elevated plus maze testing were also measured with GLM-multivariate analysis. When appropriate, Tukey's post hoc test was used. Furthermore, a factor analysis (principal component analysis: PCA) was performed over the behavioral data from both naïve modified holeboard and elevated plus maze testing, followed by an one-way ANOVA to determine strain differences in naïve behavior.

For Experiment 3, data are presented as mean of three trials per day \pm SEM (except day 1; behavior over 10 minutes with all cylinders baited). Data from days 2-10 were subjected to GLM-repeated measures to analyze progression (between strains) over days. Between strain differences on days 1-10 and within strain differences from days 8-9 (i.e., introducing the reversal) were tested by two-way ANOVA. Also here, factor analysis was performed over the behavioral data per strain to obtain relevant behavioral parameters for either $\mathrm{BALB} / \mathrm{C}$ or $\mathrm{C} 57 \mathrm{BL} / 6 \mathrm{~J}$ mice. These behavioral parameters were used to perform additional factor analyses for each testing day. In this case, behavioral structure over days was obtained with strain specific parameters.

PCA uses cross-mouse comparisons to distinguish the relation between behavioral parameters. It includes as much data as possible in each factor to minimize residual variance from the original dataset. The PCA was performed with a Varimax rotation on variables with communalities over 0.7 , that is, of which $70 \%$ of the variance is explained by the Factors extracted. The number of extracted Factors was not pre-defined; Factors with an Eigenvalue over 1 were accepted. Factor scores were subjected to a two-way ANOVA to determine differences between groups and days. $p<0.05$ was accepted as level of significance for all statistical testing.

\section{RESULTS}

Experiment 1: the neuroendocrine phenotype: markers of stress system activity

This experiment was performed to characterize central and peripheral markers of stress system activity of BALB/C and C57BL6J mouse strains.

MR and GR mRNA expression. MR and GR mRNA expression differed significantly between BALB/C and C57BI/6J mice $(F(7,5)$ 7.170, $p=0.023$; Table 1; Figure 1). C57BL/6J mice expressed significantly

Table 1. MR and GR mRNA expression as gray value of optical densities (mean \pm SEM) in hippocampus, prefrontal cortex, amygdala, and induseum griseum of BALB/C and C57BL/6J mice.

\begin{tabular}{lrc}
\hline & BALB/C & C57BL/6J \\
\hline MR mRNA & & \\
Hippocampus & $20.84 \pm 0.86$ & $23.54 \pm 0.75^{*}$ \\
Prefrontal cortex & $1.20 \pm 0.20$ & $3.15 \pm 0.47^{\text {** }}$ \\
Amygdala & $32.81 \pm 3.45$ & $37.56 \pm 2.52$ \\
Indusium griseum & $12.44 \pm 1.85$ & $2.17 \pm 1.08^{* *}$ \\
GR mRNA & & \\
Hippocampus & $26.88 \pm 1.95$ & $33.49 \pm 2.16^{*}$ \\
Prefrontal cortex & $11.13 \pm 1.48$ & $2.71 \pm 1.20^{* *}$ \\
Amygdala & $23.56 \pm 1.94$ & $23.71 \pm 2.71$ \\
\hline
\end{tabular}

${ }^{*} p<0.05$.

${ }^{* \star} p \leq 0.001$ between strains.
Table 2. GR protein expression corrected for total protein (gray values mean $\pm S E M$ ) in hippocampus, prefrontal cortex, and amygdala of BALB/C and C57BL/6J mice.

\begin{tabular}{lcc}
\hline & BALB/C & C57BL/6J \\
\hline Hippocampus & $0.36 \pm 0.03$ & $0.64 \pm 0.10^{*}$ \\
Prefrontal cortex & $0.37 \pm 0.05$ & $0.32 \pm 0.03$ \\
Amygdala & $2.21 \pm 0.56$ & $0.84 \pm 0.14^{*}$
\end{tabular}

${ }^{*} p<0.05$ between strains.

higher MR mRNA in the hippocampus and prefrontal cortex, and higher GR mRNA in the hippocampus compared to BALB/c mice. In contrast, BALB/c mice expressed significantly more GR mRNA in the prefrontal cortex. Interestingly, BALB/c mice had strong MR mRNA expression in the indusium griseum, compared to $\mathrm{C} 57 \mathrm{BL} / 6 \mathrm{~J}$ mice. The function of the indusium griseum is not known (Berger et al., 2006).

GR protein expression by Western blotting. GR protein expression was significantly different between BALB/c and C57BL/6J mice $(F(3,11)$ $3.114, p=0.030$ ). C57BL/6J mice displayed higher $\mathrm{GR}$ protein in the hippocampus compared to BALB/C mice, while BALB/C mice showed higher GR protein expression in the amygdala (Table 2). In addition, all the GR positive bands of C57BL/6J mice appeared at a slightly higher location on the blot compared to GR positive bands of BALB/C mice.

Corticosterone response to novelty stress. Corticosterone responses to novelty were strain dependent (Figure 2) with a significant main effect of strain $(F(1,79) 30.064, p=0.000)$, time $(F(5,79) 13.104, p=0.000)$ and interaction between strain and time $(F(5,79) 6.169, p=0.000)$. At 5 and 30 minutes of novelty exposure, BALB/C mice displayed two and threefolds higher plasma corticosterone concentrations compared to C57BL/6J mice $(p<0.05)$. At 60 and 120 minutes of novelty exposure, corticosterone levels were still increased compared to basal, but not different between strains. At 240 minutes, C57BL/6J mice displayed lower corticosterone concentrations than BALB/c mice $(p<0.05)$.

Experiment 2: the behavioral phenotype: unconditioned behavior in the modified holeboard and elevated plus maze

Modified holeboard. Multivariate analysis over all scored behaviors revealed a significant strain effect $(F(7,16) 2.949, p=0.035)$. Table 3 lists the significantly different behaviors during modified holeboard exposure (at least $p<0.05$ ). BALB/c mice spent almost twofold more time in the unprotected area, i.e., on the centerboard, have a sevenfold shorter latency to enter the centerboard and have a high number of stretched attends compared to the C57BL/6J mice. In contrast, C57BL/6J mice displayed a high number of rearings. Although C57BL/6J mice walked longer distances than BALB/c, it is the BALB/C mice that moved around more on the "unprotected" area of the centerboard, while C57BL/6J mice showed more movement in proximity of the walls (thigmotaxis). Figure 3 shows representative walking patterns of the BALB/C and C57BL/6J mice.

Stress-induced behavioral changes in the elevated plus maze. Multivariate analysis over all behaviors revealed significant effects for strain, condition (naïve/stress) and interaction between strain and condition $(F(9,27) 2.764, p=0.020, F(9,27) 96.626, p<0.0001, F(9,27)$ $3.951, p=0.003)$. Table 4 shows all significantly different behaviors during basal and stress induced elevated plus maze testing (at least $p<0.05)$.

Strain differences in naïve mice: BALB/c mice spent significantly more time in the open arm and correspondingly less time in the closed arm compared to $\mathrm{C57BL} / 6 \mathrm{~J}$ mice. BALB/c mice also displayed a higher number of rim dips and stretched attends, while C57BL/6J mice displayed a high number of rearings, grooming, and closed arm entries. The number of open arm entries and number of defecations did not differ between 


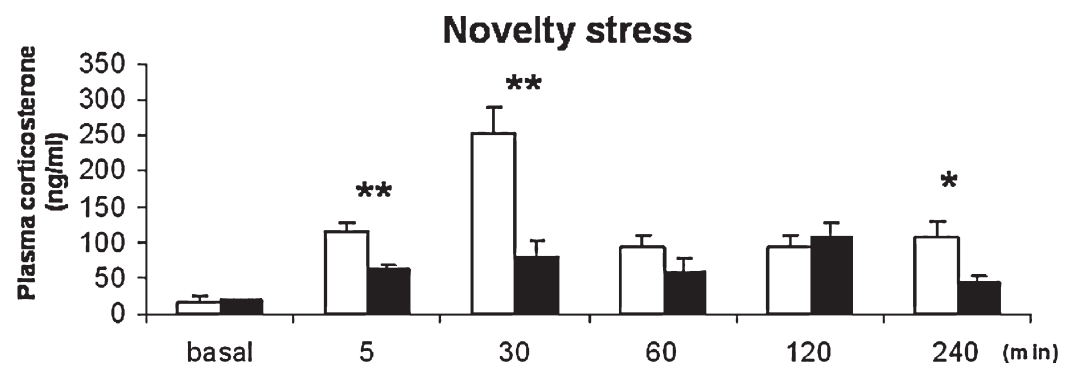

Figure 2. Corticosterone concentrations in $\mathrm{ng} / \mathrm{ml}$, basal resting and novelty-induced responses at $5,30,60,120$, and 240 minutes of novel cage exposure. $B A L B / c$ : white bars; $C 57 B L / 6 \mathrm{~J}$ : black bars ${ }^{*} p<0.05,{ }^{* *} p \leq 0.001$.

strains. Moreover, total arm entries and total distance moved were comparable between strains.

Effect of rat stress: During rat stress, BALB/c mice showed more defecations $(p<0.001)$ compared to C57BL/6J mice. Exposure to 1 hour of rat stress significantly altered the behavioral pattern of mice during subsequent testing. The number of stretched attends, rim dips, open arm entries, and time in open arm increased in C57BI/6J mice, while time in closed arms was less in this strain. Number of open arm entries in C57BL/ $6 \mathrm{~J}$ mice were increased compared to BALB/c mice. Number of rearings, stretched attends, grooming, and rim dips were increased in BALB/c mice. Also after rat stress, the distance moved was not significantly different between strains, although stress did increase the distance moved compared to naive in both BALB/C and C57BL/6J mice.

Walking patterns (Figure 4) show that naive BALB/C mice displayed more movement in the open arms compared to naïve C57BL/6J mice. After rat stress, C57BL/6J mice increase open arm exploration.

Principal component analysis (PCA). A PCA performed over behavior of naïve mice during modified holeboard and elevated plus maze testing resulted in the extraction of four factors explaining $83 \%$ of total variance. Two factors were significantly different between strains (Factor 1; $F(1,22)$ 6.657, $p=0.017$, Factor 2; $F(1,22) 6.809, p=0.016)$. These factors include variables of exploration and emotions (Table 5).

Experiment 3: the cognitive phenotype: simultaneous emotional expression and cognitive performance estimated in the modified holeboard task

Based on the previous data of stress-markers/stress responses and emotional behavior we expect differential contribution of emotion on cognitive performance in BALB/C and C57BL/6J mice.

Emotion and exploration. Multivariate analysis over all (e)motional and explorative behaviors and days revealed a significant strain difference

Table 3. Behavioral parameters of naïve BALB/C and C57BL/6J mice in the modified holeboard.

\begin{tabular}{lcc}
\hline & \multicolumn{2}{c}{ Modified holeboard } \\
\hline & BALB/c & C57BL/6J \\
\hline Rearings (no) & $24.4 \pm 4.9$ & $47.8 \pm 3.6^{*}$ \\
Stretched attends (no) & $5.2 \pm 1.3$ & $0.6 \pm 0.2^{*}$ \\
Latency first centerboard entry (s) & $17.3 \pm 3.7$ & $112.1 \pm 19.3^{\star *}$ \\
Time on centerboard (s) & $124.7 \pm 16.6$ & $73.2 \pm 9.0^{*}$ \\
Distance moved (m) & $32.2 \pm 2.7$ & $39.4 \pm 1.8^{*}$
\end{tabular}

Only behaviors with a statistical significance of $p<0.05$ are listed. no, number; s, seconds.

${ }^{*} p<0.05$.

${ }^{* *} p \leq 0.001$ between strains.
$(F(10,326) 32.018, p<0.0001)$. Multivariate analysis over data on day 1 also showed a significant strain difference $(F(10,7) 26.219, p<0.0001)$. Behaviors that showed most clear strain difference over all testing days were selected and are presented in Figure 5.

BALB/c mice spent twofold more time on the centerboard compared to C57BL/6J mice when first exposed to the setting on day $1(p=0.011$, Figure 5A). GLM showed significant progression over days 2-10 $(F(6,184) 6.004, \quad p<0.0001)$ with a significant strain difference $(F(6,184) 6.462, p<0.0001)$. BALB/c mice spent more time on the centerboard on almost all days. After introducing the reversal on day 9 , $\mathrm{BALB} / \mathrm{C}$ mice increased the time spent on the centerboard with $10 \%$ $(p=0.003)$, while the C57BL/6J mice did not.

$\mathrm{BALB} / \mathrm{c}$ mice displayed three and twofolds more cylinder visits on days 1 and 2 compared to C57BL/6J mice (day1: $p<0.0001$; day2: $p=0.013$ ). This difference was absent on days 3-10. GLM also showed significantly different progression in cylinder visits over days 2-10 $(F(6,184) 6.208$, $p<0.0001)$, with a significant strain difference $(F(6,184) 4.299$, $p=0.002$ ). BALB/c mice decreased the number of cylinder visits while visits of $\mathrm{C} 57 \mathrm{~B} \mathrm{I} / 6 \mathrm{~J}$ mice remained stable (Figure $5 \mathrm{~B}$ ). Reversal did not influence the number of cylinders visited.

C57BL/6J mice displayed an 11-fold higher number of rearings during the 10-minute trial on day $1(p<0.0001)$ and $2-5$ folds more rearing than $\mathrm{BALB} / \mathrm{C}$ mice on days 2-10. GLM showed a significant progression over days $2-10(F(6,184) 3.900, p=0.005)$, although passing statistical significance between strains $(F(6,184) 2.294, p=0.061)$. The reversal did not influence the number of rearings for both strains (Figure $5 \mathrm{C}$ ).

Cognition. Multivariate analysis over all cognitive behaviors revealed a significant strain difference $(F(9,320) 27.744, p<0.0001)$. Selected behaviors that showed most clear strain difference over all testing days are represented in Figure 6.

$\mathrm{BALB} / \mathrm{c}$ mice finished the task much faster compared to the C57BL/6J mice on days 2-10 (Figure 6A). Both BALB/C and C57BL/6J mice showed
BALB/C

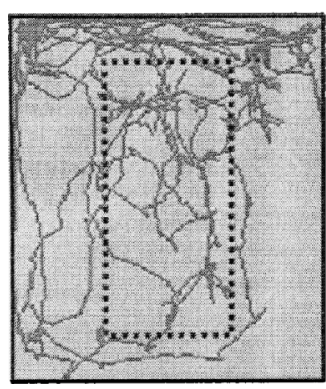

\section{C57BL/6J}

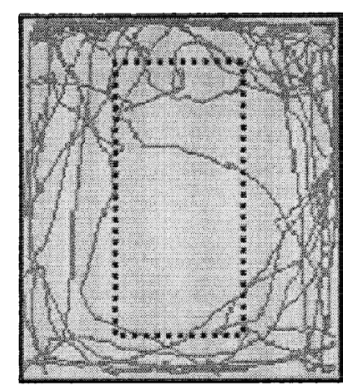

Figure 3. Representative walking patterns of BALB/C (left) and C57BL/6J mice (right) in the modified holeboard. The dotted square indicates the location of the centerboard. 
Table 4. Behavioral parameters of naïve and rat-stressed BALB/c and C57BL/6J mice in the elevated plus maze.

\begin{tabular}{|c|c|c|c|c|}
\hline & \multicolumn{4}{|c|}{ Elevated plus maze } \\
\hline & \multicolumn{2}{|c|}{ Naive } & \multicolumn{2}{|c|}{ Stress induced } \\
\hline & $\mathrm{BALB} / \mathrm{c}$ & C57BL/6J & BALB/c & C57BL/6J \\
\hline Rearings (no) & $3.2 \pm 1.0$ & $13.8 \pm 2.4^{\star \star}$ & $11.1 \pm 1.8^{\# \#}$ & $12.4 \pm 2.8$ \\
\hline Stretched attends (no) & $3.8 \pm 0.7$ & $1.4 \pm 0.3^{*}$ & $24.3 \pm 1.9^{\# \#}$ & $28.0 \pm 2.4^{\# \#}$ \\
\hline Grooming (no) & $0.9 \pm 0.2$ & $2.5 \pm 0.3^{\star \star}$ & $4.4 \pm 1.3^{\#}$ & $3.1 \pm 1.0$ \\
\hline Rim dips (no) & $10.9 \pm 1.8$ & $4.6 \pm 1.0^{\star}$ & $33.0 \pm 6.3^{\# \#}$ & $21.5 \pm 3.0^{\# \#}$ \\
\hline Open arm entries (no) & $5.3 \pm 0.8$ & $3.6 \pm 0.9$ & $5.9 \pm 0.6$ & $9.4 \pm 0.8^{\text {*\#\# }}$ \\
\hline Closed arm entries (no) & $5.3 \pm 0.7$ & $9.5 \pm 1.6^{*}$ & $7.0 \pm 1.4$ & $10.3 \pm 0.6^{*}$ \\
\hline Open arm (s) & $142.9 \pm 24.8$ & $41.3 \pm 24.4^{*}$ & $157.3 \pm 25.7$ & $109.6 \pm 14.2^{\#}$ \\
\hline Closed arm (s) & $157.1 \pm 24.8$ & $258.7 \pm 24.4^{*}$ & $119.4 \pm 23.1$ & $172.4 \pm 12.3^{\#}$ \\
\hline Distance moved (m) & $10.9 \pm 0.9$ & $10.0 \pm 0.9$ & $30.6 \pm 1.1^{\# \#}$ & $27.5 \pm 1.3^{\# \#}$ \\
\hline
\end{tabular}

Only behaviors with a statistical significance of $p<0.05$ are listed. no, number; $s$, seconds.

${ }^{*} p<0.05$.

${ }^{\star *} p \leq 0.001$ between strains.

$\# p<0.05$.

$\# \# p \leq 0.001$ within strain naive vs. stress.

a progressive decline in time to finish the task over days $2-10(F(6,184)$ $30.551, p=0.000)$. Interestingly the course of this decline differed between strains (interaction strain $\times$ days $(F(6,184) 5.144, p=0.001)$. On the last testing day (day 10 ), BALB/C mice finished the task after approximately 60 seconds, while the C57BL/6J mice needed approximately 200 seconds $(p=0.000)$. The reversal did not influence the time to finish the task in both mouse strains.

$B A L B / c$ mice showed higher reference memory ratio (i.e., the number of baited cylinder visits divided by total cylinder visits; 1.0 means no mistakes) on testing days 5 and 6 compared to C57BL/6J mice $(p<0.05)$. Introducing the reversal on day 9 abolished the strain differences, which reappeared on day 10; here the reference memory ratio of the BALB/C mice was again higher compared to the C57BL/6J mice (Figure 6B, $p<0.05)$. Both strains showed a progressive increase in reference memory ratio over days $2-10(F(6,246) 9.882, p<0.0001)$, although it did not differ between BALB/C and C57BL/6J mice.

Also the working memory of BALB/c mice (i.e., the number of food rewarded cylinder visits divided by the number of baited cylinders visited;

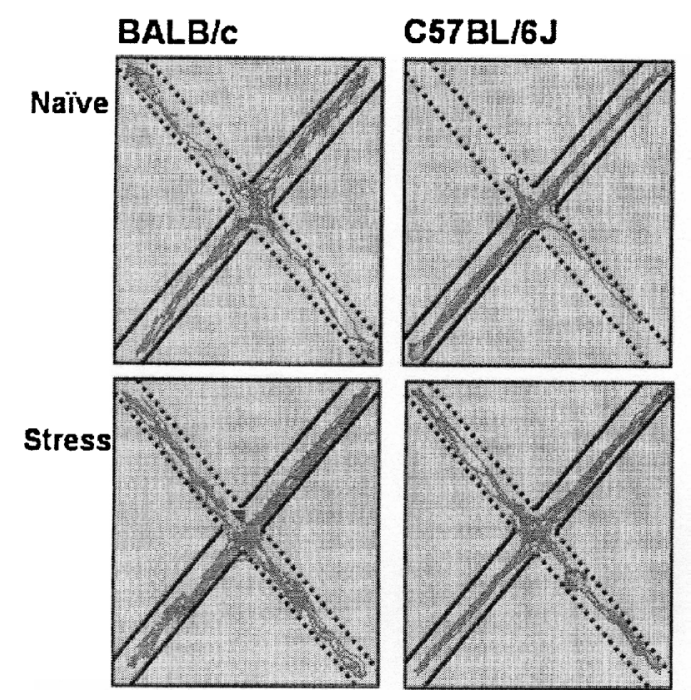

Figure 4. Representative walking patterns of BALB/c (left) and C57BL/6J mice (right) in the elevated plus maze. The dotted lines show the open arms, the straight lines the closed arms.
1 means no mistakes) was increased compared to the C57BL/6J mice on days 3,4 , and $8-10$ (Figure $6 \mathrm{C}, p<0.05$ ). Introducing the reversal did not influence working memory ratio for either mouse strain. Both strains showed a progressive increase in working memory ratio over days 2-10 $(F(6,246) 6.951, p<0.0001)$, again not different between strains.

Principal Component Analysis (PCA). A PCA performed over all behavioral data per strain resulted in the selection of four factors for $\mathrm{BALB} / \mathrm{C}$ and three factors for C57BL/6J mice, explaining respectively $86 \%$ and $83 \%$ of total variance. The behavioral parameters that were included in these factors were subsequently used in further PCA analyses (Table 6). These PCA analyses were performed per testing day (on selected behavioral parameters with a factor loading $>0.7$ ).

To allow interpretation, correlated behavioral parameters were grouped into distinct behavioral classes. We chose the following terms: motivation (latency to first cylinder visit), general exploration (number of entries on board and number of rearings), directed exploration (total number of cylinder visits), learning (time to finish task, total baited cylinders visited), and emotion (stretched attends and defecation). Distribution of these behavioral classes per factor on days $2-10$ is shown in Figure 7. The total number of extracted factors per testing day explained at least $77 \%$ of the total variance for BALB/C and $80 \%$ for C57BL/6J mice.

The pattern of behavioral classes clearly differed between BALB/c and C57BL/6J mice. The behavior of BALB/C mice appeared to be well

Table 5. Factors extracted and included behaviors with factor loading from naïve modified holeboard (MHB) and elevated plus maze (EPM) data.

\begin{tabular}{llr}
\hline & \multicolumn{1}{c}{ Behavior } & $\begin{array}{r}\text { Factor } \\
\text { loading }\end{array}$ \\
\hline Factor 1. exploration & Number of closed arm entries (EPM) & 0.88 \\
& Duration in open arm (EPM) & -0.85 \\
& Time in closed arm (EPM) & 0.85 \\
Factor 2. emotion & Rearing (EPM) & 0.78 \\
& Grooming (MHB) & 0.84 \\
& Stretched attends (EPM) & -0.83 \\
& Grooming (EPM) & 0.70 \\
\hline
\end{tabular}



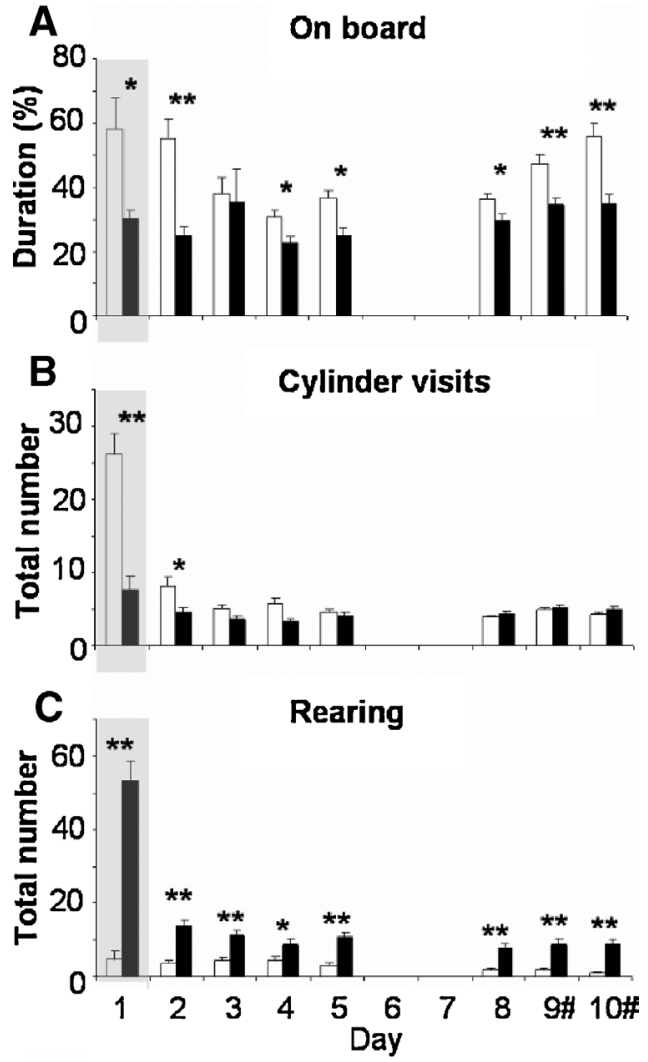

Figure 5. Emotional and explorative behavioral parameters measured on days 1-10 of holeboard testing of BALB/c (white bars) and C57BL/6J mice (black bars). (A) Percentage of time spent on the centerboard, (B) number of cylinder visits, and (C) number of rearings. The gray background on day 1 indicates data during the 10 minutes exposure; data on days 2-10 present the mean values $( \pm S E M)$ of three times 5 minutes exposure. "Baited cylinders were relocated on days 9 and 10 . ${ }^{*} p<0.05$ and ${ }^{* *} p \leq 0.001$ between strains.

structured. On days 2 and 3 learning was correlated with motivation and from day 4 on learning was correlated with directed and general exploration. Furthermore, on days with more involvement of novelty, i.e., on the first day of testing, after the 2 day break and after introducing the reversal, an additional emotional class was present in BALB/c, but not C57BL/6J mice. The behavioral classes of the C57BL/6J mice appeared to be randomly distributed over the factors. On day 2 , the behavioral class learning was correlated with directed exploration, on day 3 it was not correlated with any other class, on day 4 learning was correlated with directed exploration and motivation and on day 5 it was correlated to general exploration. From day 6 on, distribution of the behavioral classes remained similar.

\section{DISCUSSION}

BALB/C and C57BL/6J mice have characteristic emotional and cognitive behavioral patterns and a distinct regulation and responsiveness of the glucocorticoid stress system. First, we found that BALB/c mice display high risk assessment, intense exploration of the environment in the face of a higher corticosterone responsiveness to stress than C57BL/6J mice. The latter avoid anxiogenic areas, display high general exploration, and are less corticosterone responsive to novelty stress. Interestingly, prior psychosocial stress (rat exposure) dramatically changes the behavioral pattern and eliminates the strain difference in the elevated plus maze. Second, cognitive performance in a visuo-spatial learning task was superior in BALB/C compared to C57BL/6J mice. Third, "Principal Component Analysis" (PCA) compressed the large number

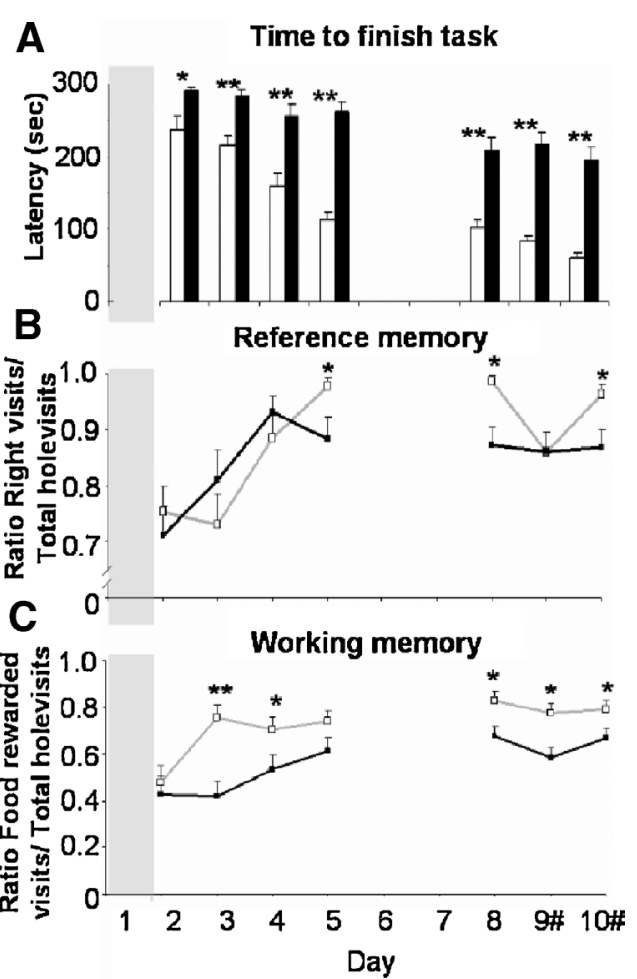

Figure 6. Cognitive parameters of modified holeboard performance of BALB/c (white bars, open squares, and gray lines) and C57BL/6J mice (black bars, filled squares, and black lines). (A) time to finish the task, (B) reference memory ratio, i.e., the number of baited cylinder visits divided by total cylinder visits, and (C) working memory ratio, i.e., the number of food rewarded cylinder visits divided by the number of baited cylinders visited. \#: Baited cylinders were relocated on days 9 and 10. ${ }^{*} p<0.05$ and ${ }^{* *} p \leq 0.001$ between strains.

of behavioral parameters by extracting factors that signify the differential contribution of exploration and emotion in basic unconditioned behavior as well as learning and memory. Moreover, this analysis demonstrates that in BALB/C mice initially independent factors of motivation and directed exploration convey during the learning process, while emotions positively contribute to learning. Here, C57BL/6J mice display less structured and a rather random behavioral organization with no emotional class. Fourth, the strain-dependent MR and GR mRNA and protein

Table 6. Behavioral parameters included in the extracted factors of BALB/C and C57BL/6J mice (X).

\begin{tabular}{lcc}
\hline & BALB/C & C57BL/6J \\
\hline Defecation (no) & $\mathrm{X}$ & \\
Baits eaten (no) & $\mathrm{X}$ & $\mathrm{X}$ \\
Cylinder visits (no) & $\mathrm{X}$ & $\mathrm{X}$ \\
Centerboard-entries (no) & $\mathrm{X}$ & $\mathrm{X}$ \\
Rearing (no) & $\mathrm{X}$ & $\mathrm{X}$ \\
Baited cylinders visited (no) & $\mathrm{X}$ & $\mathrm{X}$ \\
Stretched attend (no) & $\mathrm{X}$ & $\mathrm{X}$ \\
Repeated cylinder visits (no) & $\mathrm{X}$ & $\mathrm{X}$ \\
Eat bait (lat) & $\mathrm{X}$ & $\mathrm{X}$ \\
Time to finish task (s) & $\mathrm{X}$ & $\mathrm{X}$ \\
First cylinder visit (lat) & $\mathrm{X}$ &
\end{tabular}

Factor values $>0.7$ were selected. no, number; s, seconds; lat, latency. 

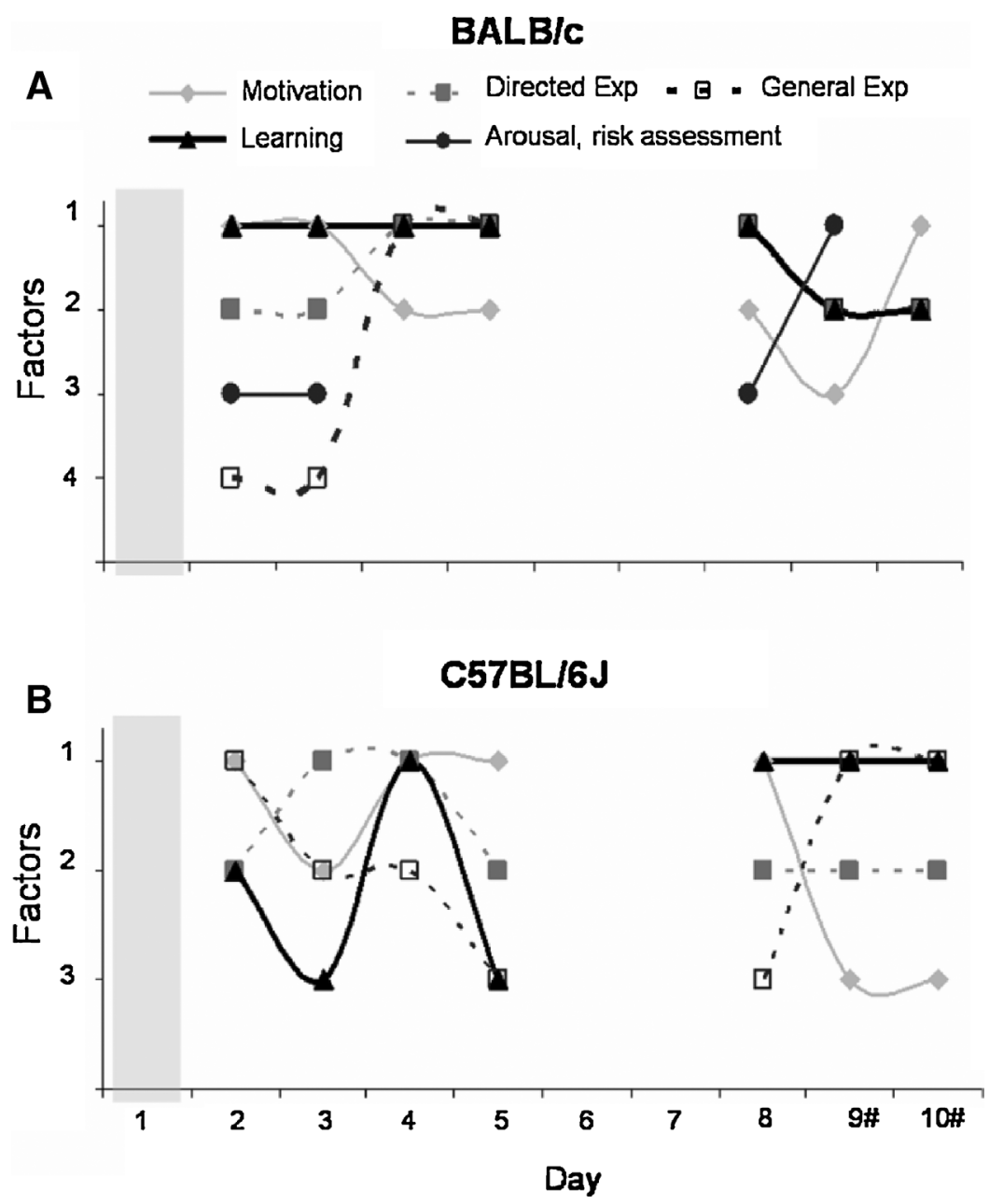

Figure 7. Distribution of behavioral classes per testing day in the extracted factors of the PCA. (A) BALB/C mice and (B) C57BL/6J mice. Symbols: Closed gray diamonds—-motivation; open squares—general exploration; closed circles—emotion; closed squares—directed exploration; closed triangles—learning. \# Baited cylinders were relocated on days 9 and 10.

expression in limbic brain areas corroborates the function of these receptors in the regulation of corticosterone secretion as well as behavior. We show not only elevated levels of GR protein in the hippocampus of C57BL/6J mice, but also different post-translational modification or splice variants of GR between strains. Although we did not manipulate discrete parameters of the stress system, the two mouse strains provide a vast amount of neuroendocrine and behavioral data that, together with PCA strongly indicate that higher stress-sensitivity and emotions related to risk assessment contribute positively to cognitive performance.

\section{Strain-dependent neuroendocrine regulation}

When placed in a novel environment, corticosterone increase in BALB/C mice is more rapid and higher compared to $\mathrm{C} 57 \mathrm{BL} / 6$ mice, which corresponds to the lower MR and GR mRNA expression of BALB/c mice. There is ample evidence from the literature that MR and GR differentially regulate corticosterone response and feedback to stress as well as the diurnal corticosterone rhythm. For example, blockade of brain MR results in a stronger increase in the corticosterone stress response during a mild stressor (Pace and Spencer, 2005; Ratka et al., 1989), and enhances corticosterone levels during circadian peak in rats (van Haarst et al., 1997). Likewise, comparable neuroendocrine response patterns in rats and mice during aging or with a specific genetic background coincide with altered MR function in the forebrain. (Dalm et al., 2005; Oitzl et al., 1995; Rozeboom et al., 2007).

Besides MR function in the proactive phase of hormonal responses, the reactive phase is controlled by GR via the negative feedback loop (de Kloet et al., 1993; Ratka et al., 1989). Lower GR function either induced by pharmacological GR antagonism or mutations of the GR show prolonged elevated secretion of corticosterone (Boyle et al., 2006; Froger et al., 2004; Karanth et al., 1997), while increased GR mRNA, either by transgene overexpression or early-life handling results in blunted initial response to acute stress and an enhanced feedback regulation (Ridder et al., 2005; Wei et al., 2007). Elevated GR mRNA expression in the hippocampus of C57BL/6J mice might therefore contribute to lower initial corticosterone response as well as faster inhibition of secretion due to negative feedback activity. Based on previous results of our group and others we may conclude that the higher hippocampal MR and GR mRNA expression of C57BL/6J mice, possibly the post-translational modification or a different splice variant of the GR protein is responsible for the lower glucocorticoid response to novelty stress, while the lower level of hippocampal receptor expression in BALB/C mice coincides with increased stress sensitivity towards novelty.

Interestingly, GR protein expression correlates with GR mRNA expression in the hippocampus, but not amygdala. BALB/C and C57BL/6J mice have similar amygdaloid GR mRNA expression, while GR protein is elevated in $B A L B / c$ mice. This discrepancy suggests that in addition to 
different MR and GR mRNA contribution to hormone concentrations and behavior, also pathways related to translation and protein stabilization (Kitagawa et al., 2007) are different between BALB/C and C57BL/6J mouse strains. Furthermore, post-translational modification or expression of different splice variants of the GR protein also seems to be different between these mice, although the consequence is yet unknown. Naturally we are aware of the fact that more factors than MR and GR contribute to the excitability of the glucocorticoid stress system. However, based on the strain-dependent differential expression of MR and GR and our knowledge of the behavioral role of MR and GR, we may predict stronger emotional behavior of $\mathrm{BALB} / \mathrm{c}$ than $\mathrm{C} 57 \mathrm{BL} / 6 \mathrm{~J}$ mice.

\section{Unconditioned behavior: strain-dependent patterns of exploration and emotion in relation to MR and GR function} Indeed, behavior of naïve BALB/C and C57BL/6J mice in the holeboard and elevated plus maze analyzed by PCA shows strain differences for exploration and emotion factors. The preferential areas of activity of BALB/C mice are the "unprotected" (anxiogenic) parts of the test boxes, i.e., open arms of the elevated plus maze and centerboard in the holeboard task. In accordance with other studies, BALB/C mice show higher risk assessment (stretched attends) than C57BL/6J mice (Augustsson and Meyerson, 2004). C57BL/6J mice avoid the open arms and centerboard and show high rearing. Before we address the interpretation of this behavior in relation to anxiety, we will highlight the strain-differences in emotional/explorative behaviors in relation to characteristics of MR and GR.

Numerous studies demonstrated the role of MR in behavioral responses to novel environments (Oitzl et al., 1997). Latest findings are derived from forebrain MR knockout mice with altered behavior during their first exposure to a learning task and reactivity to a novel object (Berger et al., 2006). Anxiety-related behavior in the elevated plus maze, open field and defensive buying test are decreased after pharmacological blockade of MR (Bitran et al., 1998; Smythe et al., 1997). This corresponds to our data in which BALB/c mice with less MR mRNA, show increased directed exploration of their environment compared to C57BL/6J mice. However, the literature is controversial as some studies show that increased MR is related to less anxiety-like behavior (Herrero et al., 2006; Lai et al., 2007; Rozeboom et al., 2007). Next to the differential interpretation of behavior as anxiety-like, one possible explanation could be a (dis)balanced contribution of GR (Brinks et al., 2007b). Low GR mRNA expression and protein as we see in the hippocampus of BALB/c mice has been correlated with less anxiety-related behavior in rats and mice (Jakovcevski et al., 2007; Kabbaj et al., 2000), while high GR mRNA or GR activation is implied in high anxiety-like behavior in C57BL/6J mice (Brinks et al., 2007b; Jakovcevski et al., 2007). In contrast to the lower GR mRNA and protein in hippocampus, BALB/c mice show higher GR mRNA in the prefrontal cortex and GR protein in the amygdala, which could be important for the higher emotionality of this strain.

An alternative explanation for the distinct behavioral patterns of C57BL/6J and BALB/C mice might lie in the initial stress response to novelty, when BALB/c mice increase their corticosterone secretion 10-fold within 5 minutes. Recently, a novel molecular mechanism for a fast nongenomic action of corticosterone has been described (Karst et al., 2005). MR, however with a low affinity for the hormone and thus activated by fast rising and high corticosterone concentrations is thought to orchestrate behavior. Behavioral consequences of short term non-genomic corticosteroid effects like increased risk assessment and altered search strategies have been reported in rats (Khaksari et al., 2007; Mikics et al., 2005). During the last few years, interest in gene $x$ environment interaction has increased. The maternal care as environmental factor in early life can program the stress system and behavior has been shown for both strains: C57BL/6J dams display high maternal care compared to $B A L B / c$ dams. GABA(A) receptor expression that is involved in anxiety (Crestani et al., 1999) is altered by maternal influences (Caldji et al.,2003;
Caldji et al.,2004). Moreover, cross-fostering demonstrated a change in MR and GR function and anxiety-like behavior (Priebe et al., 2005).

We conclude that MR and GR via their genomic and most likely also MR non-genomic effects are central molecular mechanism for behavioral regulation.

\section{Anxiety and escape behavior: stress increases the movement in the anxiogenic zones and risk assessment}

During rat stress, BALB/c mice are much more aroused than C57BL/6J mice (increased defecation). When exposed directly thereafter to the elevated plus maze, behavioral changes regarding risk assessment and arousal further increase, while time and entries into the open arms remain as high as in naïve mice. In contrast, stressed C57BL/6J mice specifically increase their risk assessment behavior together with the number of entries and time spent in the unprotected open arms to the level of BALB/C mice. Is this an anxiolytic effect of acute stress?

Most interpretations of behavior as anxiety-like are based on the measurement of a few parameters related to the avoidance of unprotected, open, so-called "anxiogenic" zones. By this definition, naïve C57BL/6J mice would be highly anxious, while naïve and stressed $\mathrm{BALB} / \mathrm{C}$ and stressed C57BL/6J would be labeled as mice with low anxiety. An anxiolytic effect of stress is unlikely as we and others showed that stress or corticosteroids increase anxiety-like behavior (Belzung et al., 2001; Brinks et al., 2007b; Jakovcevski et al., 2007). However, when anxiety becomes expressed as freezing (passive coping), exploration of the environment is prevented and cognitive performance impaired (Herrero et al., 2006). The detailed registration of behavior as suggested by Rogers et al., (1999) and subjecting the many behavioral parameters to advanced statistical analyses revealed a more refined picture of interacting emotions, exploration and general activity patterns of the mice.

Freezing, exploration of safe areas, and exploration for escape possibilities can all be expressions of anxiety. Escape behavior and stretched attends are important, often forgotten anxiety variables in maze testing (Hodges, 1996; Rogers et al., 1999). When including these behaviors, BALB/c mice are more emotional than C57BL/6J mice. Also supported by the dramatic increase in distance moved and stretched attends after acute stress, we consider escape behavior, thus an active coping style as an expression of the underlying emotion of anxiety.

\section{Strain-dependent cognitive performance: structure of behavior and response to reversal}

In this food-rewarded task, BALB/c mice are faster learners with superior reference and working memory compared to C57BL/6J mice. The behavioral pattern of BALB/C mice during learning includes an emotionality factor. Even more, finding bait in the cylinders increases the time spent on the centerboard with high directed exploration towards the cylinders, crystallizing as additional motivation factor. Our findings seem to contradict several reports of poor spatial learning abilities of BALB/c mice in the water maze (Francis et al., 1995; Van Dam et al., 2006; Yoshida et al., 2001). However, BALB/c mice did not show inferior cognitive performance when tested in a dry maze or including multiple cognitive parameters for learning and memory (Koopmans et al., 2003; Yoshida et al., 2001). The water maze is regarded as a highly stressful, aversive task for mice which prefer dry land over wet mazes (Whishaw and Tomie, 1996). Already Yoshida et al., (2001) suggested that the motivation and stress stemming from tasks are likely factors that differentially affect water maze and dry maze learning. Indeed, the apparently contradicting results underline the strain-dependent impact of stress and emotions for cognitive performance as well as the relevance for using multiple tasks with an elaborate behavioral analysis before labeling cognitive capacities of a mouse strain.

Which factors contribute to learning? PCA revealed motivation as correlate of learning in BALB/c mice during the first testing days. Goal- 
directed behavior gains relevance for performance during later stages of learning. An emotion factor is present only in BALB/c mice at times of relative novelty: at the first days of leaning, after a break of 2 days and during reversal. Here, behavior that is vulnerable to stress becomes part of the behavioral structure, i.e., risk assessment and arousal. Although this emotion factor does not correlate with learning (or any other behavioral class) we consider it likely that these initial responses to the setting contribute to subsequent learning (Touyarot et al., 2004). In our test conditions, C57BL/6J mice lack this emotion factor. A correlation between directed exploration and learning is initially present, but disappears later on. Learning and other factors do not convey, but alternate rather randomly. We may conclude that the conveyance of behavioral factors supports the superior cognitive performance of $B A L B / c$ mice, while the lack of orchestrated behavior leaves the C57BL/6J mice at a more inferior level of performance.

The design of the task allows spatial (fixed location of the baited cylinders) but also stimulus-response learning (white rings around the baited cylinders). How do mice respond to a reversal, i.e., re-location of the cylinders? A preferential use of a spatial learning strategy will be accompanied by errors and a drop in reference memory, as we see in $B A L B / c$ mice. However, the new locations are acquired very quickly and reference memory recovers to its superior level, showing only a shortlasting drop in performance. No such effect is found in C57BL/6J mice, which apparently use the visual discriminating stimulus to locate the bait: a stimulus-response learning strategy. Different memory systems contribute to these strategies: nucleus caudate is related to stimulusresponse and the hippocampus to spatial learning strategies (Steidl et al., 2006; White and McDonald, 2002). Spatial learning requires a more complex organization and processing of information, implying a higher degree of flexibility. Stimulus-response learning is rather rigid. Both strategies allow to solve the task, albeit the spatial solution appears to be the most efficient one.

Distinct MR and GR characteristics are not only modulating specific phases of memory (de Kloet et al., 1999; Oitzl and de Kloet, 1992a), but might be also related to spatial and stimulus-response strategies. MR plays a role in the appraisal of the situation as well as the flexibility of the behavioral response as evidenced by genetic and pharmacological manipulation of MR functions (Berger et al., 2006; Khaksari et al., 2007; Lai et al., 2007; Wei et al., 2007). These studies suggest that less MR, as seen in BALB/C mice, would allow rather flexible behavior and together with the increased context-related corticosterone surge, also would allow activation of GR in context to facilitate memory consolidation (Joels et al., 2006; Oitzl et al., 2001a; Roozendaal, 2002; Sandi et al., 1997). Overexpressing hippocampal MR results in more intense responses towards novel objects and in an enhancement in the consolidation of nonspatial memory (Ferguson and Sapolsky, 2007). Thus, higher levels of MR are linked to a stimulus-bound response strategy. This is what we observe in C57BL/6J mice which are characterized by elevated hippocampal MR and GR expression. The stimulus-response strategy is of advantage as long as the visual stimulus predicts the location of the bait, as it happens to be in the current task.

Considering the cognitive performance of BALB/C and C57BL/6J at large, stress-vulnerable behaviors of risk assessment and arousal (both in $B A L B / c$ mice only) in the face of an active coping style imply interacting systems of stress, emotion, and cognition to the benefit of superior cognitive performance. C57BL/6J mice as rather emotionless and less stress-sensitive phenotype demonstrate less hippocampus-guided behavior and thus, cognitive performance at a different level. The advantage of either style will be closely related with the demands of the task. Since acute stress activates emotional responses in C57BL/6J mice, increasing the emotional characteristics of the task (e.g., fear conditioning) will reveal more active coping behavior and clear stimulus-bound responses in this mouse strain. Indeed, C57BL/6J mice show an active coping style, characterized by more scanning than freezing behavior, while BALB/c mice show more freezing than scanning. So likewise, the acquisition and consolidation of fear memories was predominantly stimulus-bound in $\mathrm{C} 57 \mathrm{BL} / 6 \mathrm{~J}$ mice compared to BALB/C mice (Brinks et al., 2007a).

\section{CONCLUSION}

This study demonstrates that distinct stress system regulation by MR mRNA and GR mRNA and protein expression correlates with emotional behavior, cognitive performance, and behavioral structure in BALB/c and C57BL/6J mice. Lower hippocampal MR and GR mRNA expression, but elevated GR mRNA in prefrontal cortex and GR protein in the amygdala of $\mathrm{BALB} / \mathrm{c}$ mice coincides with increased stress vulnerability, high emotional expression, and superior spatially orientated cognitive performance. High MR and GR in C57BL/6J mice corresponds to lower stress vulnerability and cognitive performance which is stimulus-response driven. Our data contribute to the understanding how the stress system, emotion, and cognition interact under basal and stress conditions.

\section{CONFLICT OF INTEREST STATEMENT}

The authors declare that the research was conducted in the absence of any commercial or financial relationships that could be construed as a potential conflict of interest.

\section{ACKNOWLEDGMENTS}

This study was supported by the Netherlands Organization of Scientific Research NW0-Cognition 051.02.10, NW0-Aspasia 015.01.076 grant, and the Trier-Leiden IRTG program supported by NWO DN 95-429. We thank Janine Doorduin, Theo Schouten, and Servane Lachize for technical assistance and Harm Krugers and Olof Wiegert, University of Amsterdam for scientific discussions.

\section{REFERENCES}

Acevedo, S. F., Ohtsu, H., Benice, T. S., Rizk-Jackson, A., and Raber, J. (2006). Agedependent measures of anxiety and cognition in male histidine decarboxylase knockout (Hdc-/-) mice. Brain Res. 1071, 113-123.

Augustsson, H., and Meyerson, B. J. (2004). Exploration and risk assessment: a comparative study of male house mice (Mus musculus musculus) and two laboratory strains. Physiol. Behav. 81, 685-698.

Balogh, S. A., and Wehner, J. M. (2003). Inbred mouse strain differences in the establishment of long-term fear memory. Behav. Brain Res. 140, 97-106.

Belzung, C., El Hage, W., Moindrot, N., and Griebel, G. (2001). Behavioral and neurochemical changes following predatory stress in mice. Neuropharmacology 41 , 400-408.

Berger, S., Wolfer, D. P., Selbach, O., Alter, H., Erdmann, G., Reichardt, H. M., Chepkova, A. N., Welzl, H., Haas, H. L., Lipp, H. P., and Schutz, G. (2006). Loss of the limbic mineralocorticoid receptor impairs behavioral plasticity. Proc. Natl. Acad. Sci. USA 103, 195-200.

Bitran, D., Shiekh, M., Dowd, J. A., Dugan, M. M., and Renda, P. (1998). Corticosterone is permissive to the anxiolytic effect that results from the blockade of hippocampal mineralocorticoid receptors. Pharmacol. Biochem. Behav. 60, 879-887.

Blair, K. S., Smith, B. W., Mitchell, D. G., Morton, J., Vythilingam, M., Pessoa, L., Fridberg, D., Zametkin, A., Sturman, D., Nelson, E. E., Drevets, W. C., Pine, D. S., Martin, A., and Blair, R. J. (2007). Modulation of emotion by cognition and cognition by emotion. Neuroimage 35, 430-440.

Bohus, B., and de Kloet, E. R. (1981). Adrenal steroids and extinction behavior: antagonism by progesterone, deoxycorticosterone and dexamethasone of a specific effect of corticosterone. Life Sci. 28, 433-440.

Boyle, M. P., Kolber, B. J., Vogt, S. K., Wozniak, D. F., and Muglia, L. J. (2006). Forebrain glucocorticoid receptors modulate anxiety-associated locomotor activation and adrenal responsiveness. J. Neurosci. 26, 1971-1978.

Brinks, V., de Kloet, E. R., and Oitzl, M. S. (2007a). Strain specific fear behaviour and glucocorticoid response to aversive events: modelling PTSD in mice. Prog. Brain Res. 167, 257-261.

Brinks, V., van der Mark, M. H., de Kloet, E. R., and Oitzl, M. S. (2007b). Differential MR/ GR activation in mice results in emotional states beneficial or impairing for cognition. Neural. Plast, 11, Article ID 90163.

Caldji, C., Diorio, J., and Meaney, M. J. (2003). Variations in maternal care alter GABA(A) receptor subunit expression in brain regions associated with fear. Neuropsychopharmacology 28, 1950-1959.

Caldji, C., Diorio, J., Anisman, H., and Meaney, M. J. (2004). Maternal behavior regulates benzodiazepine/GABAA receptor subunit expression in brain regions associated with fear in BALB/c and C57BL/6 mice. Neuropsychopharmacology 29, 1344-11352. 
Contarino, A., Dellu, F., Koob, G. F., Smith, G. W., Lee, K. F., Vale, W., and Gold, L. H. (1999). Reduced anxiety-like and cognitive performance in mice lacking the corticotropin-releasing factor receptor 1. Brain Res. 835, 1-9.

Crestani, F., Lorez, M., Baer, K., Essrich, C., Benke, D., Laurent, J. P., Belzung, C., Fritschy, J. M., Luscher, B., and Mohler, H. (1999). Decreased GABAA-receptor clustering results in enhanced anxiety and a bias for threat cues. Nat. Neurosci. 2 , 833-839.

Dalm, S., Enthoven, L., Meijer, 0. C., van der Mark, M. H., Karssen, A. M., de Kloet, E. R., and Oitzl, M. S. (2005). Age-related changes in hypothalamic-pituitary-adrenal axis activity of male C57BL/6J mice. Neuroendocrinology 81, 372-380.

de Kloet, E. R., Oitzl, M. S., and Joels, M. (1993). Functional implications of brain corticosteroid receptor diversity. Cell Mol. Neurobiol. 13, 433-455.

de Kloet, E. R., Oitzl, M. S., and Joels, M. (1999). Stress and cognition: are corticosteroids good or bad guys? Trends Neurosci. 22, 422-426.

Dolcos, F., and McCarthy, G. (2006). Brain systems mediating cognitive interference by emotional distraction. J. Neurosci. 26, 2072-2079.

Ducottet, C., and Belzung, C. (2004). Behaviour in the elevated plus-maze predicts coping after subchronic mild stress in mice. Physiol. Behav. 81, 417-426.

Ferguson, D., and Sapolsky, R. (2007). Mineralocorticoid receptor overexpression differentially modulates specific phases of spatial and nonspatial memory. J. Neurosci. 27, 8046-8052.

Francis, D. D., Zaharia, M. D., Shanks, N., and Anisman, H. (1995). Stress-induced disturbances in Morris water-maze performance: interstrain variability. Physiol. Behav. 58, 57-65.

Froger, N., Palazzo, E., Boni, C., Hanoun, N., Saurini, F., Joubert, C., Dutriez-Casteloot, I., Enache, M., Maccari, S., Barden, N., Cohen-Salmon, C., Hamon, M., and Lanfumey, L. (2004). Neurochemical and behavioral alterations in glucocorticoid receptorimpaired transgenic mice after chronic mild stress. J. Neurosci. 24, 27872796.

Gerlai, R., Fitch, T., Bales, K. R., and Gitter, B. D. (2002). Behavioral impairment of APP(V717F) mice in fear conditioning: is it only cognition? Behav. Brain Res. 136, 503-509.

Grootendorst, J., de Kloet, E. R., Dalm, S., and Oitzl, M. S. (2001). Reversal of cognitive deficit of apolipoprotein $\mathrm{E}$ knockout mice after repeated exposure to a common environmental experience. Neuroscience 108, 237-247.

Harizi, H., Homo-Delarche, F., Amrani, A., Coulaud, J., and Mormede, P. (2007). Marked genetic differences in the regulation of blood glucose under immune and restraint stress in mice reveals a wide range of corticosensitivity. J. Neuroimmunol. 189, 5968.

Hayden, E. P., Klein, D. N., Durbin, C. E., and Olino, T. M. (2006). Positive emotionality at age 3 predicts cognitive styles in 7-year-old children. Dev. Psychopathol. 18, 409-

Herrero, A. I., Sandi, C., and Venero, C. (2006). Individual differences in anxiety trait are related to spatial learning abilities and hippocampal expression of mineralocorticoid receptors. Neurobiol. Learn. Mem. 86, 150-159.

Hodges, H. (1996). Maze procedures: the radial-arm and water maze compared. Brain Res. Cogn. Brain Res. 3, 167-181

Jakovcevski, M., Schachner, M., and Morellini, F. (2007). Individual variability in the stress response of C57BL/6J male mice correlates with trait anxiety. Genes Brain Behav. 78, 578-595.

Joels, M., Pu, Z., Wiegert, O., Oitzl, M. S., and Krugers, H. J. (2006). Learning under stress: how does it work? Trends Cogn. Sci. 10, 152-158.

Kabbaj, M., Devine, D. P., Savage, V. R., and Akil, H. (2000). Neurobiological correlates of individual differences in novelty-seeking behavior in the rat: differential expression of stress-related molecules. J. Neurosci. 20, 6983-6988.

Karanth, S. Linthorst, A. C., Stalla, G. K. Barden, N., Holsboer, F., and Reul, J. M. (1997) Hypothalamic-pituitary-adrenocortical axis changes in a transgenic mouse with impaired glucocorticoid receptor function. Endocrinology 138, 3476-3485.

Karst, H., Berger, S., Turiault, M., Tronche, F., Schutz, G., and Joels, M. (2005). Mineralocorticoid receptors are indispensable for nongenomic modulation of hippocampal glutamate transmission by corticosterone. Proc. Natl. Acad. Sci. USA 102, 19204-19207.

Khaksari, M., Rashidy-Pour, A and Vafaei, A. A (2007). Central mineralocorticoid receptors are indispensable for corticosterone-induced impairment of memory retrieval in rats. Neuroscience 21, 125-132.

Kitagawa, H. Yamaoka, I., Akimoto, C., Kase, I. Mezaki, Y, Shimizu, T, and Kato, S. (2007). A reduction state potentiates the glucocorticoid response through receptor protein stabilization. Genes Cells 12, 1281-1287.

Koopmans, G., Blokland, A., van Nieuwenhuijzen, P., and Prickaerts, J. (2003) Assessment of spatial learning abilities of mice in a new circular maze. Physiol. Behav. 79, 683-693.

Lai, M., Horsburgh, K., Bae, S. E., Carter, R. N., Stenvers, D. J., Fowler, J. H., Yau, J. L., Gomez-Sanchez, C. E., Holmes, M. C., Kenyon, C. J., Seckl, J. R., and Macleod, M. R. (2007). Forebrain mineralocorticoid receptor overexpression enhances memory, reduces anxiety and attenuates neuronal loss in cerebral ischaemia. Eur. J. Neurosci. 25, 1832-1842.

Linthorst, A. C., Flachskamm, C., Barden, N., Holsboer, F, and Reul, J. M. (2000). Glucocorticoid receptor impairment alters CNS responses to a psychological stressor: an in vivo microdialysis study in transgenic mice. Eur. J. Neurosci. 12, 283291.

Mikics, E., Barsy, B., Barsvari, B., and Haller, J. (2005). Behavioral specificity of nongenomic glucocorticoid effects in rats: effects on risk assessment in the elevated plus-maze and the open-field. Horm. Behav. 48, 152-162.
Ohl, F. Sillaber, I., Binder, E. Keck, M. E., and Holsboer, F. (2001). Differential analysis of behavior and diazepam-induced alterations in C57BL/6N and BALB/c mice using the modified hole board test. J. Psychiat. Res. 35, 147-154.

Ohl, F., Roedel, A., Binder, E., and Holsboer, F. (2003). Impact of high and low anxiety on cognitive performance in a modified hole board test in C57BL/6 and DBA/2 mice. Eur. J. Neurosci. 17, 128-136.

Oitzl, M. S., and de Kloet, E. R. (1992a). Selective corticosteroid antagonists modulate specific aspects of spatial orientation learning. Behav. Neurosci. 106, 62-71.

Oitzl, M. S., and de Kloet, E. R. (1992b). Selective corticosteroid antagonists modulate specific aspects of spatial orientation learning. Behav. Neurosci. 106, 62-71.

Oitzl, M. S., Fluttert, M., and de Kloet, E. R. (1994). The effect of corticosterone on reactivity to spatial novelty is mediated by central mineralocorticosteroid receptors Eur. J. Neurosci. 6, 1072-1079.

Oitzl, M. S., van Haarst, A. D., Sutanto, W., and de Kloet, E. R. (1995). Corticosterone, brain mineralocorticoid receptors (MRs) and the activity of the hypothalamicpituitary-adrenal (HPA) axis: the Lewis rat as an example of increased central MR capacity and a hyporesponsive HPA axis. Psychoneuroendocrinology 20, 655675

Oitzl, M. S., van Haarst, A. D., and de Kloet, E. R. (1997). Behavioral and neuroendocrine responses controlled by the concerted action of central mineralocorticoid (MRS) and glucocorticoid receptors (GRS). Psychoneuroendocrinology 22 Suppl 1, S87S93.

Oitzl, M. S., Reichardt, H. M., Joels, M., and de Kloet, E. R. (2001a). Point mutation in the mouse glucocorticoid receptor preventing DNA binding impairs spatial memory. Proc. Natl. Acad. Sci. USA 98, 12790-12795.

Oitzl, M. S., Reichardt, H. M., Joels, M., and de Kloet, E. R. (2001b). Point mutation in the mouse glucocorticoid receptor preventing DNA binding impairs spatial memory. Proc. Natl. Acad. Sci. USA 98, 12790-12795.

Pace, T. W., and Spencer, R. L. (2005). Disruption of mineralocorticoid receptor function increases corticosterone responding to a mild, but not moderate, psychological stressor. Am. J. Physiol. Endocrinol. Metab. 288, E1082-E1088.

Phelps, E. A. (2006). Emotion and cognition: insights from studies of the human amygdala. Annu. Rev. Psychol. 57, 27-53.

Priebe, K., Romeo, R. D., Francis, D. D., Sisti, H. M., Mueller, A., McEwen, B. S., and Brake, W. G. (2005). Maternal influences on adult stress and anxiety-like behavior in C57BL/6J and BALB/cJ mice: a cross-fostering study. Dev. Psychobiol. 47, 398407

Ratka, A., Sutanto, W., Bloemers, M., and de Kloet, E. R. (1989). On the role of brain mineralocorticoid (type I) and glucocorticoid (type II) receptors in neuroendocrine regulation. Neuroendocrinology 50, 117-123.

Ridder, S., Chourbaji, S., Hellweg, R., Urani, A., Zacher, C., Schmid, W., Zink, M. Hortnagl, H., Flor, H., Henn, F. A., Schutz, G., and Gass, P. (2005). Mice with genetically altered glucocorticoid receptor expression show altered sensitivity for stress-induced depressive reactions. J. Neurosci. 25, 6243-6250.

Rogers, D. C., Jones, D. N., Nelson, P. R., Jones, C. M., Quilter, C. A., Robinson, T. L., and Hagan, J. J. (1999). Use of SHIRPA and discriminant analysis to characterise marked differences in the behavioural phenotype of six inbred mouse strains. Behav. Brain Res. 105, 207-217.

Roozendaal, B. (2002). Stress and memory: opposing effects of glucocorticoids on memory consolidation and memory retrieval. Neurobiol. Learn. Mem. 78, 578-595.

Roullet, P., and Lassalle, J. M. (1995). Radial maze learning using exclusively distant visual cues reveals learners and nonlearners among inbred mouse strains. Physiol. Behav. 58, 1189-1195.

Roy, V., Merali, Z., Poulter, M. 0., and Anisman, H. (2007). Anxiety responses, plasma corticosterone and central monoamine variations elicited by stressors in reactive and nonreactive mice and their reciprocal F(1) hybrids. Behav. Brain Res. 185, 4958.

Rozeboom, A. M., Akil, H., and Seasholtz, A. F. (2007). Mineralocorticoid receptor overexpression in forebrain decreases anxiety-like behavior and alters the stress response in mice. Proc. Natl. Acad. Sci. USA 104, 4688-4693.

Sandi, C., Loscertales, M., and Guaza, C. (1997). Experience-dependent facilitating effect of corticosterone on spatial memory formation in the water maze. Eur. J. Neurosci. 9 , 637-642.

Schmidt, M. V., Enthoven, L., van der, M. M., Levine, S., de Kloet, E. R., and Oitzl, M. S. (2003). The postnatal development of the hypothalamic-pituitary-adrenal axis in the mouse. Int. J. Dev. Neurosci. 21, 125-132.

Smythe, J. W., Murphy, D., Timothy, C., and Costall, B. (1997). Hippocampal mineralocorticoid, but not glucocorticoid, receptors modulate anxiety-like behavior in rats. Pharmacol. Biochem. Behav. 56, 507-513.

Steidl, S., Mohi-uddin, S, and Anderson, A. K. (2006). Effects of emotional arousal on multiple memory systems: evidence from declarative and procedural learning. Learn. Mem. 13, 650-658.

Touyarot, K., Venero, C., and Sandi, C. (2004). Spatial learning impairment induced by chronic stress is related to individual differences in novelty reactivity: search for neurobiological correlates. Psychoneuroendocrinology 29, 290-305.

Van Dam, D., Lenders, G., and De Deyn, P. P. (2006). Effect of Morris water maze diameter on visual-spatial learning in different mouse strains. Neurobiol. Learn. Mem. 85, 164-172.

van Haarst, A. D., Oitzl, M. S., and de Kloet, E. R. (1997). Facilitation of feedback inhibition through blockade of glucocorticoid receptors in the hippocampus. Neurochem. Res. 22, 1323-1328.

Wall, P. M., and Messier, C. (2000). Concurrent modulation of anxiety and memory. Behav. Brain Res. 109, 229-241. 
Wei, Q., Hebda-Bauer, E. K., Pletsch, A., Luo, J., Hoversten, M. T., Osetek, A. J., Evans, S J., Watson, S. J., Seasholtz, A. F., and Akil, H. (2007). Overexpressing the glucocorticoid receptor in forebrain causes an aging-like neuroendocrine phenotype and mild cognitive dysfunction. J. Neurosci. 27, 8836-8844.

Whishaw, I. Q., and Tomie, J. A. (1996). Of mice and mazes: similarities between mice and rats on dry land but not water mazes. Physiol. Behav. 60, 11911197
White, N. M., and McDonald, R. J. (2002). Multiple parallel memory systems in the brain of the rat. Neurobiol. Learn. Mem. 77, 125-184.

Yoshida, M., Goto, K., and Watanabe, S. (2001). Task-dependent strain difference of spatial learning in C57BL/6N and BALB/c mice. Physiol. Behav. 73, 37-42.

Zorawski, M., and Killcross, S. (2002). Posttraining glucocorticoid receptor agonist enhances memory in appetitive and aversive Pavlovian discrete-cue conditioning paradigms. Neurobiol. Learn. Mem. 78, 458-464. 